\title{
AIR POWER IN THE CONTEMPORARY ENVIRONMENT
}

\author{
Brigadier General Patrick WOUTERS
}

\begin{abstract}
A senior officer of the NATO International Military Staff examines the evolving requirements towards alliance air forces and factors that shape procurement decisions.
\end{abstract}

Keywords: hybrid operations, network enabled capabilities, intelligence, reconnaissance, surveillance, ACCS, interoperability.

\section{Introduction}

The responsibility of NATO's Plans and Policy Division is to prepare Military Committee Decisions, deliver Military Committee advice to the North Atlantic Council and transfer Council decisions to the NATO Military Authorities for implementation. Our three main fields of expertise, and I use the term advisedly, are in the military aspects of NATO's Strategic Policy and Concepts, Defence and Force Planning and Chemical, Biological, Radiological, and Nuclear Policy.

I intend to look at Air Power in the Contemporary Environment and how it relates to both Bulgaria's national and NATO's collective security and future Air Power requirements. I will address this issue using three broad approaches: Firstly, setting the context and looking at the relative importance of air power in the region. Then I will look at the requirements for any contemporary Air Force that wishes to participate as a fully fledged NATO member, able and willing to contribute to NATO's air power dimension. Lastly, I will canter through numerous considerations, all of which are factors to varying degrees, but with a list that is by no means exhaustive.

\section{Context}

Let me therefore start by looking at the context in general terms of what I will refer to as 'national power.' Every NATO nation, or non-NATO nation for that matter, has at 
its disposal a number of tools with which it can seek to assert its place in the world or within the geographic region in which it is situated physically. Unlike location, many of the tools it can use are not physical, as a hammer is used on an anvil, but moral or spiritual, that often have influence over our psyche and ultimately affect our perception of today's globalised world. The tools will be no surprise to any of you, and sit along the lines of the use of Diplomacy, Information, Military and, last but by no means least, Economic.

Turning first to Diplomacy, the means by which we would all like to ultimately win future conflicts without ever having to cross the start line to use the vernacular of our Land Force brethren. In becoming a NATO Member alone, Bulgaria has made an important choice - choosing the pursuit of peace for its people. Military force will always remain as a potent tool to support its diplomatic efforts, as a last resort, if other peace efforts have failed.

In today's rapidly changing world, the Information domain gains dominance, doubling by the year almost as do the speed of the processors by which it is filtered, sorted, communicated, miscommunicated and, ultimately, perceived by the target audience, intended or otherwise. The onset of the 24/7 news phenomenon allows our leaders and our forces little room for manoeuvre and can be brutal in seeking the truth... or, indeed, what might be able to be sold as the truth for commercial gain. It is the informational advantage or information superiority that NATO must continue to invest in if it is to gain and maintain the advantage over its adversaries. Regrettably, the onset of the internet has allowed asymmetric aggressors to dominate the information domain with relative ease.

The next tool is that of our Military who rely on their ability to use military power to defeat or coerce their enemies, although military power is not always about 'direct' or kinetic effects. Increasingly, we are seeing the use of 'soft' or non-kinetic effects. Direct use of force is not essential for deterrence; indeed capability has a deterrent value all of its own.

Military power is perceived around the world according to defence spending estimates, and every one of us is reliant upon Economic effects. Our economic success ultimately dictates what our defence spending can be while our political masters decide what it will be - and no doubt the type and colour of the future aircraft procurement. But as well as being a tool and one of the strongest at that, economic effects can also be threats. Increasingly, we are realising that energy security is becoming a genuine threat to the stability we have strived for so long to achieve, and indeed NATO has achieved, over the last 60 years. Food, water-and human security in general-are further examples of future threats that hitherto have not caused NATO to have sleepless nights, but are likely to do so in the future. 
In wrapping up the context, I do not need to labour Bulgaria's geographic position as a former Warsaw Pact member, nor do I have to mention much about its neighbours, suffice to say it sits in a strategically important region - one in which NATO maintains a keen interest. We do not have to look back too far to see lucid examples of when the balance of power swings in one direction or the other - take the use of air power and the ground invasion during the five-day conflict between Russian and Georgia only a few years behind us, but still in our rear view mirror.

The Russian air force carried out a few hundred offensive sorties over Georgia mainly using three types of aircraft: Sukhoi-24M frontal bombers, Sukhoi-25 ground-attack aircraft, and Tupolev-22M3 long-range bombers. Georgia, which was the first to employ air power, was severely limited in what it could do, due to the small size of its air force and the overwhelming superiority, in comparative terms, of the Russian air force. Georgia's effort at developing an effective air defence system were taken seriously by Russia, and Georgia's air defence assets were targeted accordingly throughout the conflict. It shows that air command and control facilities quickly become military centres of gravity that will play a capital role in any future conflict.

Learning his own lessons from the conflict, Russia’s President Dmitry Medvedev set about reforming his military forces, despite the country's apparent success in its military conflict with Georgia. He then set out five key areas for improvement, generating reforms of the Russian armed forces that are arguably the most radical since 1945. In short, Russia aims to create a professional, permanent combat-ready army, designed for intervention in local conflicts rather than large-scale conventional operations. These proposed changes are planned to take effect by 2012, and many of them will have implications for the future of Russian air power.

After briefly examining context, let's touch now on the requirements, focussing a little more on air power.

\section{Requirements}

I say touch on, for that is really all it can be in such a short period, for to pre-judge such an important decision with a click of a mouse would be to do the decision an injustice. Moreover, outside of the guidance given in targets (formerly called force goals), it is not for NATO HQ to decide what the shape of Bulgaria's future fighter should look like, but operational requirements must come before technological ambition.

From my perspective, unless it looks like an F-16 and smells like an F-16, it really isn't a real man's fighter. Joking aside, I illustrate how life really does move on with many NATO nations' front line fighter pilot slots now filled by female pilots; technology too moves on apace. 
Technology touches on one of the first hard decisions that Bulgaria will have to make, namely the decision between on the one hand, a small number of aircraft with future technology or, on the other hand, today's technology in more palpable numbers.

In terms of value for money, how many of us can afford to buy a brand new car every time we need to replace it? Indeed, a 'previously owned' air vehicle may well give nations best value for money; a choice too that might enable far greater numbers than a new 'off the shelf' choice, let alone bespoke solutions. Some NATO partners have successfully explored the dilemma of leasing a capable fighter rather than buying outright. Again, it is ultimately the politicians who will decide, but we, the operators, must help them to make the right choice both for the nation concerned and ultimately for NATO.

So what do we want a future fighter to do? If we are to defend effectively, we must 'know our enemy.' In contemporary conflict we must at least try to understand our threats, and it is to these that I shall now turn. I'll start recalling the words of the famous Italian aviator General Giulio Douhet, who already in 1928 stated:

A man who wants to make a good instrument must first have a precise understanding of what the instrument is to be used for; and he who intends to build a good instrument of war must first ask himself what the next war will be like. ${ }^{1}$

But trying to predict what will constitute future warfare is fraught with difficulties. The recent past has seen the emergence of non-traditional adversaries, an exponential change in technologies, increasing globalisation, economic interdependence and the inevitable economic downturn all serving to cloud the picture. We are currently working to define what the concept of 'hybrid warfare' might bring to our doctrine and as most of you have probably discovered, the Allied Command Transformation (ACT) gave a good preview on the Multiple Futures we might face (see Figure 1). ${ }^{2}$

Given the likely characteristics of future conflict, most of the implications shown on the right side of Figure 1 will feature a prominent role for the air component, and this role is likely to be an evolution of the way it is currently utilised, not least because platforms procured today could be in service for the next 30 years.

It is clear that a great many factors could influence the characteristics of future conflict, but it is unsurprising that there is no consensus of what the most significant characteristics will be. It is clear that key decision-makers would be imprudent to ignore the possibility of participation in conflict across the spectrum of warfare - from high to low intensity, from major peer competitor, in nuclear or conventional war, to irregular warfare. For the air component, this range of possibilities means that its con- 


\section{NATO'S MULTIPLE FUTURES}

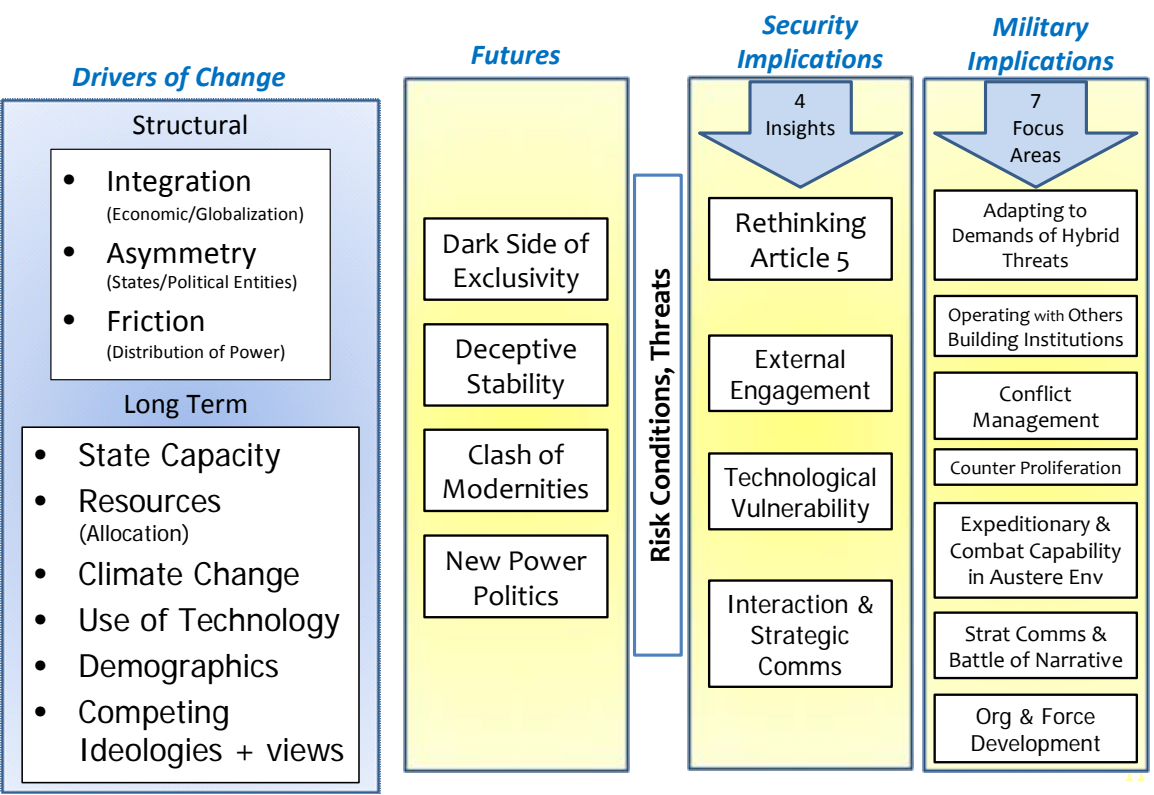

Figure 1: Military strategic framework for Defence \& Security.

stituent forces will need to be chameleon-like in order to adapt to their circumstances reflexively.

As I touched on earlier, the Russian invasion of Georgia is a case in point. Russian tactics that combined conventional force with cyber warfare to disable Georgian command and control underscored the range of threats that are now possible. Flexibility of attitude by all components will be vital in addressing these emergent challenges.

The area of irregular and possibly hybrid conflict probably presents us with the biggest challenge to our ability to adapt to the enemy's versatile behaviour. In this field alone, there are clear implications for the air component as conflicts transform, epitomized by the way Taliban and Al Qaeda have changed their modus operandi, continually trying to stay one step ahead.

The 'So what?' is that times are changing and 'putting all your eggs in one basket' is likely to limit 'future flexibility' - traditionally a tenet of Air Power. This spread betting approach could be of 'fleets within fleets' and one aircraft type or it might mean split forces, with refurbished aircraft sitting alongside shiny new specialized ones, 
and if a 'previously owned' or refurbished option were to be taken too, then it could allow all partners to have a role.

On the organisational side, air components will need to stay agile and use existing platforms in new and innovative ways whilst training alongside the other components to maximise their chances of success, whatever the type of conflict. I will return to further aspects of training later.

The air component must be prepared to fight across the full spectrum of warfare, whilst utilising airpower's strengths and characteristics to prosecute successful air campaigns in these irregular conflicts. To do this, more low-end platforms may be necessary, especially those capable of being a force-multiplier in a resource limited force, as most modern forces are these days.

The temptation for air forces to do what they have always done in the past, see a new threat as a catalyst to buy new equipment to solve that problem, should be avoided, not least to counter the rising costs of defence technologies, and the commensurate reduction in overall platforms, or borrowing at the expense of other areas across national defence capabilities.

But what about costs? Indeed, cost is probably the single most important factor in any procurement decision. With NATO entering its first ever year where resources are genuinely limited, a degree of rationalisation and re-prioritization has become necessary. In trying to balance requirements with available resources, the Military Committee is now engaged with the Strategic Commanders in weighing carefully the military risk incurred with not, or not immediately, fulfilling particular requirements. Furthermore, instead of competing entire capability areas against each other, we are looking at how the expenditure profiles on projects can be staggered in time. This approach has raised the interest of many NATO nations, but here an aspect of good coordination among allies and avoiding duplication in national capabilities comes to the fore. The reality for most of us is that resources will shape what we do now and in the foreseeable future.

That said, greater economic pressures often lead to more innovative and efficient solutions, simply because they have to be. Many examples exist within NATO of socalled smart procurement and many more of where nations have sensibly made choices that allow interoperable platforms and equipment to operate synergistically, all the while spreading risk of failure of national logistic solutions delivering 'just in time' or whatever the latest logistic buzzword is.

A good example of this synergy can be seen with the European Expeditionary F-16 Air Wing whereby, in order to increase efficiency, participating air forces make optimum use of available and complementary assets in out-of-area operations. This af- 
filiation allows for deployments involving two or more air forces, depending on the particular circumstances, which is entirely consistent with the new concept of the NATO Response Force. Through this approach, national sovereignty is respected, with each participating nation defining its level of commitment. The essential benefit of such a collaborative arrangement is synergy. Through their combined commitment, NATO nations as a group can deliver more robust and sustainable force packages than autonomous national efforts would allow, and this has shown its value in ISAF, not only for fighters, but also for helicopters.

Turning now to the last of my three areas in the procurement toolbox, applying intellectual power clearly, this section comes with a huge health warning!

\section{Considerations}

So what other considerations must we address? Much like the requirements, there are many considerations that - seen through national versus NATO lenses-may individually appear quite differently depending on from where they are viewed. I have chosen a few that might warrant further consideration.

In the post-Cold War era, the challenge of a sensible force mix concerns both larger and smaller European actors. For the smaller nations, the particular question is what particular capabilities they should provide in order to contribute to a sensible force mix on a supra-national level. These capabilities include offensive aspects such as precision-strike, defensive aspects such as theatre ballistic missile defence, or force enabling aspects such as air-to-air refuelling.

They underpin the four core air power roles - control of the air, mobility and lift, intelligence and situational awareness, and attack, both kinetic and non-kinetic. In deployed operations, a fully autonomous force must be able to meet all these roles. Yet achieving full effectiveness in all areas is, and will almost certainly remain, beyond the affordable reach of a single European nation and there should be a focus for Bulgaria.

The second reason identified to generate common approaches to air power is the shift from 'fighting in place' to deployed operations. Deployed operations actually require more roles to be covered than traditional territorial alliance defence. This particularly concerns the areas of mobility, sustainability and force protection.

Thirdly, the shift from deterrence postures to real operations revealed significant shortfalls in European force structures. Unlike the Cold War deterrence postures, real operations are unforgiving in exposing shortfalls. Capabilities not only have to exist on paper, but they must be robust, deployable and usable at short notice. Moreover, 
real operations are challenging and demanding in terms of interoperability issues, another point I will return to later.

Improvements in European defence are often presented as inextricably linked to limited defence budgets and to a lack of investment in research and development. Yet co-operative approaches to European air power might offer more value for money, as has already been highlighted.

Further alternatives include role specialisation as well as doctrinal and operational responses. Unlike the pooling of assets, role specialisation has been politically more sensitive. As a consequence, role specialisation has been taking place by defaultdue to lack of resources-rather than by a deliberate policy. Role specialisation is perceived to supposedly limit national freedom of action. In particular, nations are reluctant to become reliant on other allies for particular capabilities. Yet small nations in any case have to limit themselves to a very narrow bandwidth of roles. It would be beneficial for small nations to explore the potential of role specialisation more systematically and to acquire subject matter expertise in certain key areas, which would allow them to gain increased leverage within NATO by providing a sought-after niche capability. Reluctance to go down the path of role specialisation also contributes to the European imbalance between the shaft and the spear. Due to constrained budgets, kinetic air power capabilities routinely win in procurement stakes over force enabling capabilities. Kinetic assets are still seen as providing for a country's defence, whereas an overemphasis on force enablers is seen as excessive role specialisation. This attitude exacerbates the teeth-to-tail ratio on a supra-national level.

Nevertheless, when considering these options we must also be cognisant of the fact that today's operations are primarily conducted by NATO, the EU, or ad hoc coalitions. NATO and the EU's Common Security and Defence Policy (CSDP) complement each other. While NATO guarantees a strong transatlantic link and provides for collective defence, the CSDP is particularly suited for rapid interventions, essentially in support of the well-known Petersberg tasks. Accordingly, a natural division of labour between the two organisations is shaping up. Hence, in order to guarantee political freedom of action, co-operative ventures should be equally available to both NATO and to Europe's Security and Defence Policy. This flexibility is important in a politically fragile environment, when it comes to the projection of military power.

Also, effective European air power is not simply a matter of size and resources rather, it is a question of balanced, interoperable, and usable capabilities. Moreover, it is a question of political will and a question of an air force's qualities regarding professionalism, training, education, and attitude.

So what attributes should be considered at the outset that would ensure any future investment offers value for money? 
As one of four transformational drivers, Network Enabled Capability (NEC) is probably the one capability that offers the greatest 'room for improvement' across NATO. As we drive forward into an uncertain future, one of the few certainties we have is of the pre-eminence of information. The traditional 'centralized command, decentralised execution' is now challenged, once seen as the 'long screw-driver' effect from those who had the relevant feeds that allowed them, and only them, to have full situational awareness.

Nowadays, this shared situational awareness is no longer the sole preserve of higher command, and can be shared down to squadron level. This effectively means that the need for centralised control is less. Furthermore, it frees up the Air Component Commander to do what he is supposed to do - namely Command. Work done by the Joint Air Power Competence Centre (JAPCC) suggests that there can now be a new model for what might be termed 'Network Enabled Command' whereby 'mission command' can be given to Wing and Squadron Commanders. They can then utilise their experience to achieve the mission with greater effect, less resource, or both; operational and tactical decisions can be devolved to the Commander best placed to make them. However, the greatest benefit of this improved availability of informational feeds can be illustrated in the support our Air Forces can offer the ground commander.

\section{Intelligence, Surveillance and Reconnaissance (ISR)}

Fast jet Intelligence, Surveillance, and Reconnaissance (ISR) plays an important role on the battlefield where there is never enough ISR to go around regardless of the form it takes. Targeting pods have been utilised in recent years to fill a 'non-traditional' ISR gap and, in doing so, their dynamic employment allows live feeds to be down-linked via ROVER terminals held with land forces, thereby bringing NEC into the air/land environment, right on the battlefield where it is needed most. This utility has many benefits, by day and by night, filling the intelligence and information void and offering the local ground commander the best possible spatial awareness. Tactics continue to evolve and important advances in this area have secured much needed benefits for the troops on the ground. Non kinetic 'shows of force' highlight Alliance presence and overwatch, while at the same time identifying critical information in the fight against improvised explosive devices. These joint tactics now include escort procedures that have already saved many lives; the Taliban are less likely to ambush patrols, when they see, or more usually just hear, that a convoy is being supported by armed escort, fixed or rotary wing.

The use of contemporary data-link technology such as Link 16 has been fundamental to these integrated approaches. Added to the ability to provide pin-point accuracy through the use of modern precision guided munitions (PGMs), such contemporary 
Joint Team tools provide for an extremely potent and credible force. However, our adversaries also adapt. The military must be prepared to engage anywhere but, with the will of the people the 'objective to be won,' serious difficulties arise for the air component when opponents use the urban environment to shield themselves. Air platforms find it extremely difficult to maintain reference upon fleeting targets-particularly fast jets, given their speed, operating height and turning circles-even with the most capable of sensor pods. By continually adapting and learning this operational art, both kinetic and non-kinetic effects allow us to maintain a significant asymmetric advantage in the close battle and provide the assured support that our troops expect and deserve. This brings me to my next point, namely that of training and its importance.

\section{Training}

It is widely acknowledged that the nature of warfare has changed and continues to evolve at an alarming rate. While we must not train solely for the last war, Afghanistan illustrates the criticality of sound training. Moreover, it is likely we will have some form of presence there for the foreseeable future. Operations in Afghanistan have also highlighted the need for common, multinational joint training and standardized procedures for the conduct of close air support. Forces currently conducting operations within ISAF are using common guidance documents. It is imperative that these forces employ capable operators if we are to avoid fratricide and minimise collateral damage.

Many nations already have well established training programmes, while others could benefit from the collective training, benefits and experience of those Allies who have returned most recently from theatre. This passing-on of knowledge helps inexperienced operators to minimise 'making the same mistakes.' The output of a robust lessons-learned process can be communicated too and then reinforced by participation in pre-deployment exercises, and other large joint combined exercises like the 'Flag' series held in the US and Canada each year. Another example of the benefits of collective know-how is in opening the night window and other specialised domains of air operations: an air force that is not used to working with night vision goggles, laser technology and GPS-based mission planning software can get a serious head start by planning smartly and training for interoperability, a topic to be explored further below.

Probably the most stark operational example of why this training is so valuable can be illustrated by looking at Rules of Engagement (ROE). Joint Tactical Air Controllers on the ground do a fantastic job of supporting troops in contact. Their job is made all the more difficult as the ROE and national caveats they work with often change depending on with which nation's aircraft they are operating. These political 
constraints are unlikely to go away, but of course they do complicate the controller's (and pilot's) ability to engage targets effectively. Add on to this differing ROE for the ground unit they are supporting and the message is clear. There are many recent examples of what happens when we get it wrong. But timely air support to isolated land forces fighting in close quarters and far away from friendly strongholds is arguably the capability area where the man should remain in the loop.

Much as army leaders would not advocate robots replacing their best infantrymen, we too have to make a strong case to our political observers and decision-makers that unmanned platforms are not the panacea the budgeteers would like us to believe. Especially for nations that do not own and operate a significant space infrastructure that supports the massive bandwidth requirements and communications satellites to manage swarms of unmanned drones effectively, the manned fighter will remain the only sure way to make worthwhile contributions. While it is true that many elements of air power can be delivered through unmanned applications, it is certainly not the sole method and cannot be relied on alone.

The Provincial Reconstruction Teams or the Operational Mentoring and Liaison Teams that NATO puts across Afghanistan should be able to count-in a matter of minutes, not hours - on an allied voice that will deliver ordnance where they see fit to get them out of harm's way. Here is also how air power can contribute to the Comprehensive Approach, by providing a reassuring presence for those that realise it one the ground and contributing to the secure environment necessary for Stabilisation and Reconstruction operations.

\section{Interoperability}

It is no good deploying a thirsty fighter without the requisite Air to Air capability with which to sustain it - likewise, clearly if one nation's aircraft are to plug into other NATO enablers, they must be interoperable, both in the air and on the ground. The Alliance as a whole must continually strive to improve interoperability at all levels. Procurement in any nation allows fresh opportunity to improve that nations' interoperable equipment, but it is more than just being able to receive aviation fuel. Interoperability covers everything from the ability of aircraft to carry and deliver ordnance down to the compatibility of specific tools and lubricants on the flight line. Equally important, however, interoperability is also about harmonized procedures and training.

On the procedural side, the success of the Alliance air policing task is dependant not only on military to military interoperability, but also on civil-military cooperation and coordination required for the relevant feeds of air traffic management information. 
On the training side, this is where NATO really adds value. Aside from contributing to NATO's collective security, Alliance Air Forces can reap the benefits from participation in the large-scale training exercises, I mentioned earlier. As operating tactics and procedures change in operational theatres, so too do the complexity of the training sets offered to the training audience on these exercises. Without the requisite training for operators and enablers alike before deployment, or employment, the 'customer' is rarely supported as best as he or she could be.

Finally, on the logistic side, interoperability is where being part of an Alliance as NATO will count most when spare parts, maintenance and ordnance can be shared at short notice on a deployed location in Italy during the Balkan wars or Kandahar in Afghanistan.

\section{ACCS}

ACCS as a major capability upgrade has the potential to greatly improve support to NATO operations and the effectiveness of fighters. It ensures interoperability not only with NATO systems, but also with other national systems and external interfaces numbering with over 160 different types. These common interfaces allow other nations to both provide and receive critical information that enables air safety assurance. ACCS receives and provides information to other command and control systems (ground, maritime, and national) including tactical resources such as sensors, weapon systems, and airborne assets that all form a core function within Network Centric Operations. Notwithstanding funding constraints in the global downturn, NATO ACCS is fundamental to having a fully integrated air and missile defence in the future.

Very recently, important work has been done at NATO HQ to provide this capability to the new NATO countries and I am confident that a solution will be found to include Bulgaria in this circle.

\section{Risk}

Finally, I would like to touch on risk. There are differences in the way military and civilian equipment is procured. The production and delivery of military 'effect' requires the development of relatively small numbers of capable equipment, suitable people and training. Perhaps most importantly, it takes time; it is rarely a quick or instantaneous process and as a consequence once a capability has gone it becomes extremely expensive to regain. Air platforms, touted as being capable of performing swing/multi-roles can become very expensive indeed.

For instance, the JSF/F35's ability to undertake intelligence functions, perform surveillance, targeting, close air support, and air defence duties concurrently, across a 
range of war fighting activities and locations, ranging from counter insurgency to medium scale warfare is not yet fully proven.

If, or when, it is sufficiently proven, the numbers required will become the focus of attention. Defining how many aircraft are needed to provide all of the capabilities that are required necessitates mathematical modelling, which should take account of capability enhancements anticipated.

However, as time progresses and costs rise, the carefully worked out figures, defining how many aircraft are needed, are likely to be revisited to incorporate a degree of 'risk.' Pressures on government spending often result in 'savings rounds' which, with the enduring perception that there is fat in the military budget, cause the numbers game to be revisited again and again. Each time a layer of risk is added, the ability of the aircraft to perform one or more of the roles it was originally envisaged to perform could be seriously challenged. Reducing the numbers of a defined operational requirement due to lack of resources diminishes operational capability, concurrency or readiness at a stroke.

General Sir David Richards' (ex COM ISAF) at a recent keynote speech to the Royal United Services Institute in UK warned that if the (military) forces continued to try "to do a bit of everything" then they would risk "failure across the board."”

Should we be maintaining a balanced force, with sufficient agility to flex from counterinsurgency operations to large-scale war fighting, or should we be focusing our priorities on likely activity, and funding those critical capabilities properly?

Wars and conflicts are not easily predictable. Who anticipated the Falklands conflict, or that our forces would be spending years in Iraq and Afghanistan? After the actions of Russia against Georgia do we need to re-focus defence to be sufficiently prepared for a conventional war in continental Europe?

\section{Conclusions}

In concluding, I would like to reiterate a few key points. The future is extremely difficult if not impossible to predict and as Douhet teaches us, in his views of over 80 years ago, we must try to understand what future conflicts will look like and thus how our military equipment should be utilized.

The tools of national power for any nation continually vary according to the political and military-strategic environment at the time. Presently, the global downturn has affected all nations as well as NATO itself, and we all have to balance requirements with resources. The financial constraints this imposes on defence budgets and NATO as an organisation are far reaching, and likely to affect the Alliance for some time to 
come, but key is to identify smartly where military risk can be taken, by federating efforts multinationally and working towards a sensible capability mix.

If the next 10 years are anything like the last 10 years, then one of the few certainties that exist is that we can expect more change and new threats that have hitherto not yet painted on our radars. An unpredictable future, when viewed in conjunction with a severe lack of resources across the Alliance, necessitates well considered procurement decisions in conjunction with savings and efficiencies in each of our military forces. Within the air component, this means collaborative approaches across combat and combat support forces and between nations too, for no single European nation can afford to achieve full effectiveness in all areas.

\section{Notes:}

1 Giulio Douhet, Command of the Air (USAF Warrior Studies) (Office of Air Force History, United States Government Printing Office, 1983).

2 For details on the NATO Multiple Futures Project see its website at www.act.nato.int/ multiplefutures.

3 "Twenty-first Century Armed Forces: Agile, Useable, Relevant," RUSI Land Warfare Conference (London, Whitehall, 23-25 June 2009), <http://www.rusi.org/events/ref: E496B737B57852/info:public/infoID:E4A4253226F582>.

Brigadier General PATRICK WOUTERS is Deputy Assistant General of the Plans and Policy Division within the International Military Staff of NATO Headquarters since August 2009. An experienced fighter pilot, he has served as F-16 Dual Capable Airbase Kleine Brogel in Belgium and Deputy Belgian Military Representative to NATO. 